\title{
Are sex and educational level independent predictors of dementia and Alzheimer's disease? Incidence data from the PAQUID project
}

\author{
L Letenneur, V Gilleron, D Commenges, C Helmer, J M Orgogozo, J F Dartigues
}

Unité INSERM 330, Université Victor

Segalen, Bordeaux, France

L Letenneur

V Gilleron

D Commenges

C Helmer

J M Orgogozo

J F Dartigues

Département

Universitaire de

Neurologie, Hôpital

Pellegrin, Bordeaux,

France

J M Orgogozo

J F Dartigues

Correspondence to: $\mathrm{Dr} \mathrm{L}$ Letenneur, Unité INSERM 330, Université Victor Segalen, Bordeaux II, 146, rue Léo Saignat, 33076 Bordeaux Cedex, France. Telephone 003355757 1588; fax 003355699 1360; email Luc.letenneur@

bordeaux.inserm.fr

Received 23 October 1997 and in final form

8 September 1998

Accepted 22 September 1998

\begin{abstract}
Objectives-To examine the age specific risk of Alzheimer's disease according to sex, and to explore the role of education in a cohort of elderly community residents aged 65 years and older.

Methods-A community based cohort of elderly people was studied longitudinally for 5 years for the development of dementia. Dementia diagnoses were made according to the DSM III $R$ criteria and Alzheimer's disease was assessed using the NINCDS-ADRDA criteria. Among the 3675 non-demented subjects initially included in the cohort, 2881 participated in the follow up. Hazard ratios of dementia were estimated using a Cox model with delayed entry in which the time scale is the age of the subjects.
\end{abstract}

Results-During the 5 year follow up, 190 incident cases of dementia, including 140 cases of Alzheimer's disease were identified. The incidence rates of Alzheimer's disease were $0.8 / 100$ person-years in men and 1.4/100 person-years in women. However, the incidence was higher in men than in women before the age of 80 and higher in women than in men after this age. A significant interaction between sex and age was found. The hazard ratio of Alzheimer's disease in women compared with men was estimated to be 0.8 at 75 years and 1.7 at 85 years. The risks of dementia and Alzheimer's disease were associated with a lower educational attainment (hazard ratio $=1.8, p<0.001$ ). The increased risk of Alzheimer's disease in women was not changed after adjustment for education.

Conclusion-Women have a higher risk of developing dementia after the age of 80 than men. Low educational attainment is associated with a higher risk of Alzheimer's disease. However, the increased risk in women is not explained by a lower educational level.

(F Neurol Neurosurg Psychiatry 1999;66:177-183)

Keywords: dementia; sex; education; incidence

Several incidence studies on Alzheimer's disease and other types of dementia in different countries and continents ${ }^{1-12}$ have shown a steady increase in the incidence of dementia according to age. This increase is essentially due to Alzheimer's disease, which is the main cause of dementia. Several risk factors of dementia and Alzheimer's disease have been studied, among them sex. Previous prevalence surveys have found an increased risk among women. ${ }^{13}{ }^{14}$ Most of the incidence studies failed to confirm such a significant association until an analysis of incidence data from the Kungsholmen Project showed an association between Alzheimer's disease and sex. ${ }^{15}$ This study, which was one of the first population based incidence studies to report such a result, was based on a cohort of subjects aged 75 years and older, living in an area in Stockholm (Sweden). Incident cases of dementia and Alzheimer's disease were ascertained 3 years after the baseline assessment. Incidence of Alzheimer's disease was higher in women than in men in all age groups. Age specific incidence increased in women, whereas the incidence was stable after the age of 80 in men. The risk of dementia was increased by 1.9 in women and the risk of Alzheimer's disease by 3.1. A possible explanation is the biological differences between men and women but the possible influence of confounders such as social life or education cannot be ruled out.

The effect of education on the risk of dementia and Alzheimer's disease is still controversial. Several prevalence surveys have reported an increased prevalence of Alzheimer's disease in poorly educated people $\left(\right.$ Katzman $\left.^{16}\right)$, but several case-control or population based studies failed to confirm this association. ${ }^{17-20}$ The main weakness of these cross sectional studies is the possible differential participation rate according to education. Highly educated people experiencing the early signs of dementia might refuse to participate, leading to an artificial increase of the proportion of poorly educated subjects among cases. Only prospective studies can reduce this bias. However, few results with incidence data are available. Stern et $a l^{11}$ found an increased risk of Alzheimer's disease in subjects with less than 8 years of schooling, whereas Cobb et a $l^{2}$ failed to find such an association.

The effect of education could either be quantitative-that is, with a linear relation between the number of years of education and the risk of dementia, or qualitative - that is, with a threshold effect at a given level of education. If a threshold effect is demonstrated, it can be postulated that the important factor is intellectual ability rather than education itself. This hypothesis is supported by a study analysing data recorded in nuns ${ }^{23}$ reporting that low linguistic ability in early life was a 
strong predictor of poor cognitive function and Alzheimer's disease in late life.

This paper aims to examine the age specific risk of Alzheimer's disease with special interest in the differential incidence in men and women according to age, and to explore the role of education in a cohort of elderly community residents aged 65 years and older.

\section{Methods}

SAMPLE

The PAQUID research programme was designed to study prospectively a representative random sample of people aged 65 years and over living in Gironde and Dordogne, two administrative areas in the south west of France. Subjects were randomly chosen from the electoral rolls of 75 parishes. Three criteria had to be met for subjects to be included in the study. They had: (1) to be at least 65 years of age by 31 December 1987, (2) to be living at home at the time of the initial data collection phase, (3) to have given their informed consent to participate in the study. A three step random procedure based on the electoral rolls stratified by age, sex, and size of the demographic unit was performed. This procedure led to a selection of 5554 elderly subjects living at home.

DATA COLLECTION

Baseline screening

Subjects were informed by mail that they had been chosen to participate in a study on the health status and living conditions of people aged 65 years and over. Then they were contacted by telephone or visited directly at home when they did not have a telephone. Subjects who agreed to participate were seen by a psychologist specially trained for home interviews. The baseline variables registered included sociodemographic factors, living conditions and habits, subjective and objective health measures, a comprehensive functional assessment, depressive symptomatology measured by the CES-D (Center for Epidemiological Study Depression) scale ${ }^{24}$ personal medical history, current symptoms and diseases, and neurosensory deficiencies. A more complete description of the baseline data collected in the PAQUID study has been published previously. $^{725}$ Among the sociodemographic data, we considered age in years, sex, and education with four levels: no schooling, primary school level (equivalent to 1 to 5 years of schooling), secondary school level (6 to 12 years of schooling), and university level (over 12 years of schooling). The higher diploma attained was also recorded.

Intellectual functioning was examined through a series of psychometric tests that were among the most sensitive for following cognitive decline in elderly people. The test battery included an evaluation of global mental status (mini mental state examination), ${ }^{26}$ visual memory (Benton's visual retention test), ${ }^{27}$ verbal memory (Wechsler's paired associates), ${ }^{28}$ verbal fluency (Isaacs set test), ${ }^{29}$ visuospatial attention (Zazzo's cancellation test), ${ }^{30}$ and simple logical reasoning (Wechsler's digit symbol test). ${ }^{31}$
Diagnosis of dementia

After the psychometric evaluation, the psychologists systematically completed a standardised questionnaire designed to obtain the A (memory impairment), B (impairment of at least one other cognitive function) and $\mathrm{C}$ (interference with social or professional life) criteria for DSM-III $\mathrm{R}$ dementia. ${ }^{32}$ This questionnaire had been previously validated with a good interobserver reliability between the psychologist and the neurologist on the basis of the DSM-III criteria. In a second stage, subjects who met these first three DSM-III R criteria for dementia were seen by a senior neurologist who confirmed and completed the DSM-III R criteria for dementia, and filled in the NINCDS-ADRDA criteria ${ }^{33}$ and the Hachinski score ${ }^{34}$ to document the diagnosis of dementia and its aetiology: probable or possible Alzheimer's disease or other type of dementia. An informant, when available, was consulted by the neurologist.

\section{Follow up}

Subjects were re-evaluated following the same procedure as for the baseline screening 1 year, 3 years, and 5 years after the initial visit in Gironde and 3 and 5 years after the initial visit in Dordogne. The case finding and the aetiological categorisation of incident cases of dementia followed the same procedure at each follow up assessment as for the baseline screening. However, to improve the sensitivity of the detection of incident cases, another criterion was added for the selection of subjects for the second stage (neurological examination). Subjects were selected for this stage if they met the criteria for DSM-III R dementia or if they had experienced a cognitive decline of more than two points at the MMSE score.

\section{STATISTICAL ANALYSIS}

Two statistical methods were used to analyse the results. A descriptive approach using age specific incidence was carried out. In a second analysis, a Cox model with delayed entry was performed to estimate hazard ratios and to adjust for several covariates. To study the characteristics of people who refused to participate in the follow up or died before it, logistic regression analyses were performed.

Age specific incidence was estimated using the person-years method. ${ }^{35}$ The basic method used to estimate age specific incidence rates is to determine for each individual the amount of observation time contributed to a given age by calendar period category and to sum up those contributions for all cohort members so as to obtain the total number of person-years of observation in that category. For instance, a subject observed at age 74 years and followed up for 5 years, contributed for 1 year in the age group 65-74 years, and for 4 years in the age group 75-84 years. For subjects with more than one follow up evaluation, person-years were calculated as the time between the baseline visit and the last follow up examination if the subject remained non-demented. For a demented subject, we considered half of the time between the last visit in which the 
subject was non-demented and the first visit in which the subject was diagnosed as demented.

The hazard ratios (HRs) of dementia or Alzheimer's disease were estimated using a Cox proportional hazard model with delayed entry, in which the time scale is the age of the subjects. When using a proportional hazards model, the form of the risk is not specified. Thus it is best to use this function to model the time variable that is expected to have the largest effect on the hazard (in this case age, which is no longer included as a covariate). Indeed, several authors have advocated that in the study of age associated diseases, the appropriate time scale for survival models is age rather than time since the baseline survey. ${ }^{35-38}$ As we studied incident cases, the subjects could participate in the analysis only if they had not experienced dementia before their inclusion. The sample is left truncated because subjects are observed conditionally on the fact that they have not developed a dementia before entering the cohort. This selection can be dealt with using the staggered entry or delayed entry option available in most Cox model software. With this option, a subject participates to the "at risk set" from the age at entry in the cohort to the age of censorship or age of outcome. The Cox model with delayed entry avoids making parametric assumptions on the relation between age and the risk of Alzheimer's disease. By contrast, if age is included as a covariate, the logarithm of the hazard is linear in age. When age related explanatory variables such as education are studied, a parametric model of age may produce correlated residuals leading to a spurious association of the explanatory variables and the risk of the disease. ${ }^{39}$

As for the person-years method, the age of onset of dementia was estimated by the mean age between the last visit when the subject was non-demented and the first visit when the subject was diagnosed as demented. This midpoint imputation is a reasonable procedure to estimate the HRs when interval widths are not too large. ${ }^{4041}$

\section{Results}

Of the 5554 contacted subjects, 3777 (68.0\%) agreed to participate in the study. Nonresponders did not differ from responders in age, sex, or educational level. ${ }^{42}$ Among the 3675 initially non-demented subjects in the cohort, $794(21.6 \%)$ did not participate in the follow up because they died $(n=365,9.9 \%)$, or because they were lost to follow up $(n=13$, $0.4 \%$ ) or refused the follow up screenings $(n=416,11.3 \%)$. At least one complete follow up evaluation was performed on 2881 subjects $(78.4 \%)$.

\section{DEATHS}

A logistic regression analysis was performed, excluding subjects who refused to participate, in which being dead before the interview was the dependent variable. The results showed that at baseline, the deceased subjects were older $(\mathrm{OR}=1.09,95 \%$ confidence interval (95\% CI) 1.08-1.11), more often men
$(\mathrm{OR}=1.99,95 \%$ CI 1.57-2.53), and had a lower MMSE score $(\mathrm{OR}=1.08,95 \%$ CI $1.05-$ 1.12) than participants. Educational level was not different.

REFUSALS

A logistic regression analysis was performed, excluding subjects who died before the interview, in which being a refusal was the dependent variable. The results showed that at baseline, the subjects who refused were younger $(\mathrm{OR}=0.95,95 \% \mathrm{CI} 0.94-0.97)$, more often women $(\mathrm{OR}=1.32$, 95\% CI 1.06-1.64), and had a lower education $(\mathrm{OR}=1.5,95 \% \mathrm{CI}$ 1.18-1.90) than participants. The MMSE score was not different.

INCIDENCES OF DEMENTIA, ALZHEIMER'S DISEASE, AND OTHER DEMENTIAS ACCORDING TO SEX

Of the 2881 reevaluated subjects, 190 were diagnosed with dementia during the follow up and 140 were diagnosed with Alzheimer's disease; 76 met the criteria for probable Alzheimer's disease and 64 the criteria for possible Alzheimer's disease. Overall incidence of dementia and Alzheimer's disease were estimated as $1.59 / 100$ person-years and $1.17 / 100$ person-years respectively. The incidence of dementia, Alzheimer's disease, and other types of dementia according to sex are given in table 1. Among the 1203 men who had contributed to the follow up (4955 person-years), 64 cases of dementia and 42 cases of Alzheimer's disease were diagnosed and 126 cases of dementia and 98 cases of Alzheimer's disease were diagnosed among the 1678 women who had contributed to the follow up (6987 person-years). Hence, the overall incidence of dementia was estimated as $1.3 / 100$ personyears in men and $1.8 / 100$ person-years in women (0.8 and 1.4 for Alzheimer's disease respectively). The incidence of Alzheimer's disease was higher in men than women before 80 years, and higher in women than men after 80 years. The incidence rates of other dementias were similar according to sex. The risk of Alzheimer's disease was assessed by a Cox model using age as the baseline time. Because a non-proportionality of the incidence rates with age was suspected, an interaction between sex and age was tested. Both sex and the interaction age by sex were significant (log likelihood ratio test $=7, p=0.03$ ). The hazard ratio of a woman developing Alzheimer's disease was then estimated to be 0.82 at age 75 , and to be 1.71 at age 85 . When other dementias were studied, neither sex $(p=0.47)$, nor the interaction between age and sex $(p=0.49)$, were found to be significant (log likelihood ratio test $=0.74$, $\mathrm{p}=0.69)$.

EDUCATIONAL LEVEL

The distribution of educational level is given in table 2. We studied the risk of Alzheimer's disease in subjects with no schooling and in subjects with a primary school level, taking subjects with a secondary or university level as the referent category. We found a higher risk of developing dementia in subjects with no schooling $(\mathrm{HR}=1.93, \mathrm{p}=0.04)$ and in subjects 
Table 1 Age specific incidence of dementia, Alzheimer's disease, and other dementias according to sex. PAQUID 1989-95. $n=2881$

\begin{tabular}{|c|c|c|c|c|}
\hline \multirow[b]{2}{*}{ Age } & \multicolumn{2}{|l|}{ Men } & \multicolumn{2}{|l|}{ Women } \\
\hline & No of cases & $\begin{array}{l}\text { Incidencel } 100 \\
\text { person-years }\end{array}$ & No of cases & $\begin{array}{l}\text { Incidence/ } 100 \\
\text { person-years }\end{array}$ \\
\hline \multicolumn{5}{|c|}{ Dementia: } \\
\hline 65-69 & 3 & 0.35 & 2 & 0.18 \\
\hline $70-74$ & 10 & 0.63 & 7 & 0.36 \\
\hline $75-79$ & 24 & 1.90 & 29 & 1.70 \\
\hline $80-84$ & 16 & 1.93 & 43 & 3.30 \\
\hline $85-89$ & 8 & 2.45 & 26 & 3.73 \\
\hline $90+$ & 3 & 3.18 & 19 & 7.03 \\
\hline \multicolumn{5}{|c|}{ Alzheimer's disease: } \\
\hline $65-69$ & 2 & 0.23 & 0 & 0.00 \\
\hline $70-74$ & 5 & 0.31 & 6 & 0.31 \\
\hline $75-79$ & 15 & 1.19 & 18 & 1.06 \\
\hline $80-84$ & 11 & 1.33 & 32 & 2.46 \\
\hline $85-89$ & 7 & 2.14 & 24 & 3.44 \\
\hline $90+$ & 2 & 2.12 & 18 & 6.66 \\
\hline \multicolumn{5}{|c|}{ Other dementias: } \\
\hline $65-69$ & 1 & 0.12 & 2 & 0.18 \\
\hline $70-74$ & 5 & 0.31 & 1 & 0.05 \\
\hline $75-79$ & 9 & 0.71 & 11 & 0.65 \\
\hline $80-84$ & 5 & 0.60 & 11 & 0.84 \\
\hline $85-89$ & 1 & 0.31 & 2 & 0.29 \\
\hline $90+$ & 1 & 1.06 & 1 & 0.37 \\
\hline
\end{tabular}

Table 2 Distribution of educational level and diploma. PAQUID 1989-95. $n=2881$

\begin{tabular}{lccc}
\hline & $n(\%)$ & Men (\%) & Women (\%) \\
\hline No education & $120(4.2)$ & $42(3.5)$ & $78(4.7)$ \\
Primary school without diploma & $812(28.2)$ & $291(24.2)$ & $521(31.0)$ \\
Primary school with diploma & $1286(44.6)$ & $546(45.4)$ & $740(44.1)$ \\
Secondary school without diploma & $346(12.0)$ & $144(12.0)$ & $202(12.0)$ \\
Secondary school with diploma & $171(5.9)$ & $79(6.5)$ & $92(5.5)$ \\
University level & $146(5.1)$ & $101(8.4)$ & $45(2.7)$ \\
\hline
\end{tabular}

who attained only a primary school level $(\mathrm{HR}=1.49, \mathrm{p}=0.02)$. However, this categorisation does not seem to be the best one. Most of the subjects only have a primary school level (table 2), and among these subjects, $61 \%$ (1286 of 2098) passed the primary school diploma. Among subjects who only have a secondary school level, 33\% (171 of 517) passed the secondary school diploma. We performed a series of analyses to determine the best cut off and found that the model with the highest log likelihood was one in which subjects with no education or without a primary school diploma were considered as having a low education.

\section{CONFOUNDING EFFECT OF EDUCATIONAL}

ATTAINMENT

The association between dementia and sex might be explained by a confounding effect of education as there were more women than men in the lower education group $(35.7 \%$ v $27.7 \%)$. To test this hypothesis, we ran three successive models including sex and the age by sex interaction (model 1), education alone (model 2), and both variables (model 3) (table 3 ). The hazard ratios of sex and education were unchanged when sex was adjusted for education. Thus a confounding effect of education seems unlikely to explain the excess risk of dementia or Alzheimer's disease in older women. No interaction between educational level and age was found, suggesting that the relation between educational level and Alzheimer's disease does not vary according to age.

INTERACTION OF SEX AND EDUCATION

To determine if the higher rate of Alzheimer's disease in women could be modified by education, a model with sex, education, interaction between sex and age, and interaction between sex and education was tested. Sex and the interaction between sex and age remained significant, whereas the interaction between sex and education was not significant $(\mathrm{p}=0.72)$. Thus, education is not an effect modifier for sex.

\section{Discussion}

Several conclusions can be drawn from this study. Firstly, incidence of Alzheimer's disease is higher in women than men after 80 , whereas the incidence is higher in men before the age of 80. The different progression of the incidence according to sex is not found when other dementias are analysed. In addition, incidence of other dementias seems to decrease in both sexes after 85 years. Secondly, this incidence study confirms that subjects with a lower educational level are at higher risk of developing Alzheimer's disease. Thirdly, adjusting for education does not change the association between sex and risk of Alzheimer's disease.

In women, an increased risk of dementia and Alzheimer's disease has been reported in several incidence studies, but without significant differences. ${ }^{191243}$ Other studies $^{810}$ also reported a higher incidence of dementia in women, but the significance of the results was not given. Two studies reported a significantly higher incidence of dementia ${ }^{5}$ or Alzheimer's disease $^{15}$ in women, but both samples were studying subjects over 85 years and 75 years of age respectively. In the Framingham study, Bachman et $a l^{2}$ did not find any difference of incidence according to sex. Finally, two studies

Table 3 Study of the independent effect of sex and educational attainment on dementia and Alzheimer's disease. PAQUID 1989-95. $n=2881$

\begin{tabular}{|c|c|c|c|c|c|c|}
\hline & \multicolumn{3}{|l|}{ Dementia } & \multicolumn{3}{|l|}{ Alzheimer's disease } \\
\hline & $H R(95 \% C I)$ & $p$ Value & $\begin{array}{l}\text { Log } \\
\text { likelihood }\end{array}$ & $H R(95 \% C I)$ & $p$ Value & $\begin{array}{l}\text { Log } \\
\text { likelihood }\end{array}$ \\
\hline Model 1 & & & -1106.78 & & & -796.87 \\
\hline $\mathrm{Sex}^{\star}($ female $v$ male $)$ & $0.396(0.09-0.90)$ & 0.033 & & $0.395(0.06-1.17)$ & 0.081 & \\
\hline Age by sex & $1.072(1.014-1.132)$ & 0.013 & & $1.076(1.007-1.149)$ & 0.029 & \\
\hline Model 2 & & & -1101.83 & & & -794.72 \\
\hline Education & $1.83(1.37-2.44)$ & $<0.001$ & & $1.81(1.30-2.53)$ & $<0.001$ & \\
\hline Model 3 & & & -1098.66 & & & -791.22 \\
\hline $\mathrm{Sex}^{\star}($ female $v$ male $)$ & $0.376(0.082-0.857)$ & 0.027 & & $0.378(0.061-1.125)$ & 0.072 & \\
\hline Age by sex & $1.072(1.014-1.132)$ & 0.013 & & $1.076(1.007-1.149)$ & 0.030 & \\
\hline Education & $1.82(1.36-2.42)$ & $<0.001$ & & $1.78(1.27-2.45)$ & $<0.001$ & \\
\hline
\end{tabular}

* The hazard ratio is given for a woman aged 65. The hazard ratio of developing Alzheimer's disease for a women aged 85 years is : $0.395 \times(1.076)^{(85-65)}=1.71$ 
reported results similar to ours-that is, a higher incidence of dementia ${ }^{3}$ or Alzheimer's disease $^{11}$ in men before 75 years, and a higher incidence in women afterwards. However, none of these studies reported a significant modification of the effect of sex according to age. Our study is the first to show a significant difference of the age specific incidence of dementia according to sex and the first to adjust for education, a potential confounding factor.

This different pattern of risk among men and women might be related to biological differences. The different genetic and hormonal characteristics could explain a delay in the occurrence of dementia in women. Several studies have reported a negative association between oestrogen replacement therapy and risk of Alzheimer's disease. ${ }^{44}$ This might explain the lower incidence found in the youngest women, leading to an adjustment of the incidence afterwards. However, in view of the age of inflexion-that is, around 80 years, this hypothesis supposes a long term action of the oestrogens, which has not been shown yet.

Differences between men and women should not be reduced to a biological one. Social characteristics are also important and may play the part of confounders in our results. Educational level is one of these confounders. We showed an association between dementia or Alzheimer's disease with lower educational attainment in men and women. We defined low educated people as subjects with no education or subjects with a primary school level without diploma. In our sample, most subjects had attained a primary school level. Among the generations studied, it was usual to stop training at this stage. However, this did not mean that people who stopped were not able to reach a secondary level. Thus the primary school level itself does not seem to be the best indicator of their cognitive capabilities and the achievement or not of the primary school diploma seems to provide a more adequate threshold for a dichotomy. Several studies have reported an association between low education or low occupational history and an increased risk of developing dementia or Alzheimer's disease in prevalent cases ${ }^{16}{ }^{19-48}$ or in incident cases. $^{321}$ However, Cobb et $a l^{22}$ did not find an association between education and incident cases of Alzheimer's disease in the Framingham study, although an association was found between non-Alzheimer's disease dementias and low educational attainment. Mortimer and Graves ${ }^{49}$ suggested that education could induce dendritic growth in the brain and that people with high levels of education would be protected to some degree against Alzheimer's disease. Another hypothesis was expressed by Snowdon et $a^{23}$ who studied linguistic ability among nuns. They found that low linguistic ability in early life was a strong predictor of poor cognitive function and Alzheimer's disease in late life and suggested that low linguistic ability may be an early expression of Alzheimer's disease neuropathology. Plassman et $a \bar{l}^{0}$ found similar results when they correlated a general learning ability test administered to inductees into the United States armed forces with cognitive tests performed in late life. They showed that cognitive performances in late life were related to cognitive ability measured in early adult life. These results were supported by two studies which used brain imaging to assess the association between cerebral blood flow and education ${ }^{51}$ or between cerebral metabolism and premorbid measures of intelligence $e^{52}$ in subjects with similar levels of severity of clinical dementia. Both studies showed that greater cerebral metabolic deficits were associated with higher level of education or premorbid ability, indicating that Alzheimer's disease was more advanced in these subjects.

Our results are consistent with these studies as obtaining a primary school diploma may be considered as an indicator of premorbid intelligence. Our findings also suggest that increasing the number of years of education does not decrease the risk of developing dementia. It rather suggests that people who reached a threshold (who passed a relatively difficult diploma) have a lower risk, whether they continued to go to school or not. However, it is not possible to strictly show that untrained or unsuccessful pupils have a higher risk of developing dementia in later life. Subjects who failed the examination might be involved later in less demanding cognitive tasks, leading to lower brain stimulation and a more limited cognitive reserve. These subjects might also be more likely to be exposed to toxic substances as they were practising rural and manual occupations more often.

Although in our sample women were less educated on average, the association between low education and Alzheimer's disease was seen both in men and women. Thus, the difference in incidence found according to sex could not be explained by a confounding effect or a modification effect of education.

Another confounder that has been analysed in this cohort is wine consumption. In a previous article, ${ }^{53}$ we showed that moderate wine consumption was associated with a lower risk of developing Alzheimer's disease. As wine consumption is higher in men than in women, it could act as a confounder. However, after adjustment for wine consumption, the association between Alzheimer's disease and sex remained unchanged. Both sex and the age by sex interaction were still significant.

Several other points need to be discussed. The number of refusals may bias our results. Refusals were younger, more often women, and were on average less educated. On the one hand, this could lead to an underestimation of the incidence of dementia in women younger than 80. However, when the analysis was limited to subjects aged 80 years and older at baseline (647 subjects and 83 with dementia), the hazard ratio of Alzheimer's disease in women was close to significance $(\mathrm{HR}=1.72$, 95\% CI $0.97-3.04, p=0.06)$ and the magnitude of the association remained unchanged. On the other hand, as it is expected that low educated people would have a higher incidence of dementia, the higher rate of lower educated subjects among refusals might result in a loss of 
power, but is unlikely to bias the negative association between education and incidence of dementia.

The problem of underdiagnosis of dementia in subjects with a higher educational level is more of concern. In our study, some of the subjects were selected to be seen by the neurologist if they experienced a decline in ability in the neuropsychological tests during the follow up. Although there is some variability in the test scores, the performance of a nondemented subject should remain stable throughout the period of study. The diagnosis of dementia at follow up implies a substantial decline from the initial performance and the observation of the decline of cognitive performances reduces the chance of misdiagnosing a demented individual. Actually, in our sample, low educated subjects lost on average 5.02 points on the MMSE score before being diagnosed as demented, whereas subjects with higher education lost on average 4.96 points.

Another problem is the lack of independence between the data collection on educational level and the diagnosis of dementia. In a prospective cohort study such as this, it is not realistic to try to interpret the evolution of cognitive performances without taking into account the educational level of the subject. It is likely that knowing the results of the initial prevalence study of PAQUID, the senior neurologists who validated the incident cases were more restrictive in making the diagnosis of dementia in subjects with lower education. Even though impossible to document or quantify, this bias could have only lowered the rate of diagnosis of dementia in this higher risk group.

In conclusion, the present findings confirm the higher rate of Alzheimer's disease in older women. We also confirmed that the incidence was higher in men before 80 years. This association did not disappear after adjustment for education. Our results on education are consistent with previous studies showing that premorbid measures of intelligence in early life were predictors of cognitive impairment in late life. We thank Dr A Jorm for his helpful comments. This research
benefited from an INSERM-NH and MRC fellowship. The benefited from an INSERM-NH and MRC fellowship. The whole PAQUID project was funded by: Aluminium Péchiney; ARMA (Institut du Cerveau); Association Recherche et
Partage; AXA; Caisse Nationale d'Assurance Maladie des Travailleurs Salariés; Caisse Primaire d'Assurance Maladie de la vailleurs Salariés; Caisse Primaire d'Assurance Maladie de la Dordogne; CAPIMMEC; Conseil Général de la Dordogne; Conseil Général de la Gironde; Conseil Régional d'Aquitaine; CRI; DANONE; Direction Régionale des Affaires Sanitaires et
Sociales d'Aquitaine; 2010 MEDIA; Fondation de France; Sociales d'Aquitaine; 2010 MEDIA; Fondation de France;
INSERM; MGEN; Ministère de la Recherche et de la Technologie; Mutualité Sociale Agricole de la Dordogne; Mutualité Sociale Agricole de la Gironde; NOVARTIS Pharma.

1 Aronson MK, Ooi WL, Geva DL, et al. Dementia: age-dependent incidence, prevalence and mortality in the old old. Arch Intern Med 1991;151:989-92.

2 Bachman DL, Wolf PA, Linn R, et al. Incidence of dementia and probable Alzheimer's disease in a general population: the Framingham study. Neurology 1993;43:515-19.

3 Bickel H, Cooper B. Incidence and relative risk of dementia in an urban elderly population. Findings of a prospective field study. Psychol Med 1994;24:179-92.

4 Copeland J, Davidson I, Dewey M, et al. Alzheimer's disease, other dementia, depression, and pseudo dementia: prevalence, incidence, and three-year outcome in Liverpool. Br f Psychiatry 1992;161:230-9.

5 Gussekloo J, Heeren T, Izaks G, et al. A community based study of the incidence of dementia in subjects aged 85 years and over. $\mathcal{F}$ Neurol Neurosurg Psychiatry 1995;59:507-10.
6 Kokmen E, Beard CM, O'Brien PC, et al. Is the incidence of dementing illness changing? A 25 year time trend study in Rochester,

7 Letenneur L, Commenges D, Dartigues JF, et al. Incidence of dementia and Alzheimer's disease in elderly community residents of south-western France. Int $\mathcal{F}$ Epidemiol 1994;23: 1256-61.

8 Molsa PK, Marttila R, Rinne U. Epidemiology of dementia in a Finnish population. Acta Neurol Scand 1982;65:541-52.

9 Paykel ES, Brayne C, Huppert FA, et al. Incidence of dementia in a population older than 75 years in the United Kingdom. Arch Gen Psychiatry 1994;51:325-32.

10 Rorsman B, Hagnell O, Lanke J. Prevalence and incidence of senile and multi-infarct dementia in the Lundby study: a of senile and multi-infarct dementia in the Lundby study: a 1957-72. Neuropsychobiology 1986;15:122-9.

11 Schoenberg B, Kokmen E, Okazaki H. Alzheimer's disease and other dementing illnesses in a defined United States population: incidence rates and clinical features. Ann Neurol 1987;22:724-9.

12 Yoshitake T, Kiyohara Y, Kato I, et al. Incidence and risk factors of vascular dementia and Alzheimer's disease in a defined elderly Japanese population: the Hisayama study. Neurology 1995;45:1161-8.

13 Jorm AF, Korten AE, Henderson AS. The prevalence of dementia: a quantitative integration of the literature. Acta Psychiatr Scand 1987;76:465-79.

14 Rocca WA, Hofman A, Brayne C, et al. Frequency and distribution of Alzheimer's disease in Europe: a collaborative study of 1980-90 prevalence findings. Ann Neurol 1991;30: 381-90.

15 Fratiglioni L, Viitanen M, Von Strauss E, et al. Very old women at highest risk of dementia and Alzheimer's disease: incidence data from the Kungsholmen project, Stockholm. Neurology 1997;48:132-8.

16 Katzman R. Education and the prevalence of dementia and Alzheimer's disease. Neurology 1993;43:13-20.

17 Chandra V, Philipose V, Bell PA, et al. Case-control study of late onset probable Alzheimer's disease. Neurology 1987;37: 1295-300.

18 Shalat SL, Seltzer B, Pidcock C, et al. Risk factors for Alzheimer's disease: a case control study. Neurology 1987;37:1630-3.

19 Fratiglioni L, Grut M, Forsell Y, et al. Prevalence of Alzheimer's disease and other dementias in an elderly urban population: relationship with age, sex and education. Neurology 1991;41:1886-92.

20 Beard M, Kokmen E, Offord K, et al. Lack of association between Alzheimer's disease and education, occupation, marital status or living arrangement. Neurology 1992;42. 2063-8.

21 Stern Y, Gurland B, Tatamichi TK, et al. Influence of education and occupation on the incidence of Alzheimer's disease. $¥ A M A$ 1994;271:1004-10.

22 Cobb JB, Wolf PA, White R, et al. The effect of education on the incidence of dementia and Alzheimer's disease in the Framingham study. Neurology 1995;45:1707-12

23 Snowdon DA, Kemper SJ, Mortimer JA, et al. Linguistic ability in early life and cognitive function and Alzheimer's disease in late life. Findings from the Nun study. $\mathscr{F} A M A$ 1996;275:528-32.

24 Radloff L. The CES-D scale: a self-report depression scale for research in the general population. Applied Psychological Measurement 1977;1:385-401.

25 Barberger-Gateau P, Chaslerie A, Dartigues JF, et al. Health measures correlates in a French elderly population: the measures correlates in a French elderly

26 Folstein MF, Folstein SE, Mc Hugh PR. Mini-mental state. A practical method for grading the cognitive state of A practical method for grading the cognitive state of
patients for the clinicians. $尹$ Psychiatr Res 1975;12:189-98.

27 Benton A. Manuel pour l'application du test de rétention visuelle. Applications cliniques et expérimentales. Paris: Centre de psychologie appliquée, 1965

28 Wechsler D. A standardized memory scale for clinical use. $\mathcal{F}$ Psychol 1945;19:87-95.

29 Isaacs B, Akhtar A. The set test: a rapid test of mental function in old people. Age Aging 1972;1:222-6.

30 Zazzo R. Test des deux barrages. Actualités pédagogiques et psychologiques. Neuchatel: Delachaux et Niestlé, 1974

31 Wechsler D. Wechsler adult intelligence scale manual. New York: Psychological Corporation, 1981.

32 American Psychiatric Association. Diagnostic and statistical manual of mental disorders, edition 3 revised. Washington, DC: APA, 1987. (DSM IIIR.)

33 Mc Khann G, Drachman D, Folstein M, et al. Clinical diagnosis of Alzheimer's disease: report of the NINCDSADRDA Work group under the auspices of the Department of Health and Human Services Task force on Alzheimer's disease. Neurology 1984;34:939-44.

34 Hachinski VC, Iliff LD, Zilhka F, et al. Cerebral blood flow in dementia. Arch Neurol 1975;32:632-7.

35 Breslow N, Day N. Statistical methods in cancer research. Vol . Lyon: International Agency for Research on Cancer, World Health Organisation, 1987. (Sci Publ No 82.)

6 Hyde J. Testing survival under right censoring and left truncation. Biometrika 1997;64:225-30.

37 Korn EL, Graubard BI, Midthune D. Time-to-event analysis of longitudinal follow-up of a survey: choice of the timescale. Am f Epidemiol 1997;145:72-80.

38 Commenges D, Letenneur L, Joly P, et al. Modelling age-specific risk: application to dementia. Stat Med 1998;17:1973-88. 
39 Commenges D, Letenneur L, Joly P. RE: Serum transferrin saturation, stroke incidence, and mortality in women and men. The NHANES I epidemiologic followup study. $A m \mathcal{F}$ Epidemiol 1997;146:683-4

40 Law CG, Brookmeyer R. Effect of mid-point imputation on the analysis of doubly censored data. Stat Med 1992;11: $1569-78$

41 Joly $\mathrm{P}$, Commenges D, Letenneur L, et al. A penalized likelihood approach for arbitrarily censored and truncated data: application to age-specific incidence of dementia. Biometrics 1998;54:185-94.

42 Dartigues JF, Gagnon M, Michel P, et al. Le programme de recherche Paquid sur l'épidémiologie de la démence. Méthodes et résultats initiaux. Rev Neurol 1991;147:225-30.

43 Brayne C, Gill C, Huppert FA, et al. Incidence of clinically diagnosed subtypes of dementia in an elderly population. Cambridge project for later life. Br f Psychiatry 1995;167 255-62.

44 Kawas C, Resnick S, Morrison A, et al. A prospective study of estrogen replacement therapy and the risk of developing Alzheimer's disease: the Baltimore Longitudinal Study of Aging. Neurology $1997 ; 48: 1517-21$.

45 Paganini-Hill A, Henderson VW. Estrogen deficiency and risk of Alzheimer's disease in women. Am $\mathcal{f}$ Epidemiol 1994;140:256-61
46 Zhang M, Katzmann R, Salmon D, et al. The prevalence of dementia and Alzheimer's disease in Shanghai, China: impact of age, gender and education. Ann Neurol 1990;27: 428-37.

47 Ott A, Breteler MMB, Vanharskamp F, et al. Prevalence of Alzheimer's disease and vascular dementia: association with education. The Rotterdam study. BMF 1995;310:970-3

48 Bonaiuto S, Rocca WA, Lippi A, et al. Education and occupation as risk factors for dementia: a population-based case-control study. Neuroepidemiology 1995;14:101-9.

49 Mortimer JA, Graves A. Education and other socioeconomic determinants of dementia and Alzheimer's disease. Neurology 1993;43(suppl 4):S39-44.

50 Plassman BL, Welsh KA, Helms $M$, et al. Intelligence and education as predictors of cognitive state in late life: a 50-year follow-up. Neurology 1995;45:1446-50.

51 Stern Y, Alexander GE, Prohovnik I, et al. Inverse relationship between education and parietotemporal perfusion ship between education and parietotemporal perfusion
deficit in Alzheimer's disease. Ann Neurol 1992;32:371-5.

52 Alexander GE, Furey ML, Grady CL, et al. Association of premorbid intellectual function with cerebral metabolism in Alzheimer's disease: implication for the cognitive reserve in Alzheimer's disease: implication for the cogn
hypothesis. Am f Psychiatry 1997;154:165-72.

53 Orgogozo JM, Dartigues JF, Lafont S, et al. Wine consumption and dementia in the elderly: a prospective community study in the Bordeaux area. Rev Neurol 1997;153:185-92. 